\title{
Strongly positive anti CCP antibodies in patients with sacroiliitis or reactive arthritis post E. Coli infection: a mini case-series based review
}

Authors: Miljyot Singh Sangha ${ }^{1,2^{*}}$, Matthew Liam Wright ${ }^{2^{*}}$ and Coziana Ciurtin ${ }^{2}$

${ }^{1}$ University College London Medical School
${ }^{2}$ University College London Hospitals NHS Foundation Trust, Department of Rheumatology

*these two authors contributed equally to the study

Corresponding author: Coziana Ciurtin, PhD, FRCP - Department of Rheumatology, University College London Hospital NHS Foundation Trust, 250 Euston Road, London, NW1 2PG, email: c.ciurtin@ucl.ac.uk; phone +44(0)2034479035, fax +44 (0)2034479268.

\section{The authors declared no conflicts of interest.}

\section{ABSTRACT:}

We report here on four cases of patients with strongly positive anti citrullinated cyclic peptides (anti-CCP) antibodies and clinical features of seronegative spondyloarthritis (SpA) and reactive arthritis. The four patients had various clinical presentations: one had an initial diagnosis of seropositive rheumatoid arthritis (RA) with involvement of the sacroiliac joints (similar to previous reports of the association of two diseases); one had a clinical picture of reactive arthritis following an episode of an E. Coli positive urinary tract infection; and two had asymmetrical sacroiliitis (SII), but no evidence of peripheral joint involvement (never reported before). In all cases, high titres of anti CCP antibodies were found. We present a comparison of the clinical manifestations, radiographic features and treatment regimens of these cases. Our report supports previous literature data of possible overlap existing between $\mathrm{RA}$ and SpA, but also presents for the first time the association of high titres of anti-CCP antibodies with SII and reactive arthritis in patients with no peripheral small joint involvement. 


\section{INTRODUCTION}

RA is a chronic autoimmune, inflammatory condition, characterised by a symmetrical deforming polyarthritis with a higher prevalence amongst women (1). Involvement of the axial skeleton is rare except for the cervical spine (2). The diagnosis of RA is made based on the revised 2010 ACR/EULAR classification criteria, which combine clinical and laboratory parameters (3). RA is associated with the presence of rheumatoid factor (RF) in approximately $70 \%$ of patients and anti-CCP antibody in $60-70 \%(4,5)$. The presence of anti-CCP antibodies is highly specific (around 90\%) for RA $(6,7)$. RA is a multifactorial disease influenced by various genetic, family and lifestyle factors $(7,8)$. Smoking is one documented association, with smokers having a higher incidence of RF positive disease when compared to non-smokers (9).

In contrast, the spondyloarthropathies (SpAs) are a constellation of inflammatory arthritic conditions characterised by the absence of rheumatoid factor and anti-CCP, hence the distinction of the group as 'seronegative' arthritides (10). In addition, their main clinical feature is an inflammatory arthritis of the axial skeleton which commonly manifests as inflammatory back pain typically affecting younger patients ( $<45$ years old). In particular, involvement of the sacroiliac joint (SIJ), defined as SII, is the hallmark of the disease, being considered the most common manifestation and initial site of joint involvement. Like RA, SpA is diagnosed based on well-defined criteria, including clinical and imaging modalities, such as $\mathrm{X}$-ray and magnetic resonance imaging (MRI) $(11,12)$.

Reactive arthritis or "sterile inflammatory arthritis" typically presents as an acute oligoarticular arthritis of the larger joints of the lower limb. Importantly it is preceded by an episode of urethritis or dysentery 1-4 weeks before the onset of symptoms (13). Diagnosis of reactive arthritis is also made clinically, but with a clear history of previous infection within the last month. Reactive arthritis may be distinguished from the most common SpA, ankylosing spondylitis (AS), by the pattern of the SII and increased frequency of peripheral joint involvement (14). Whereas the inflammation of SIJ is frequently symmetrical in AS, it tends to be more asymmetric in reactive arthritis. In all of these arthritides, inflammatory markers such as CRP and ESR can be raised, but it is increasingly recognised that in some cases the joint inflammation is not reflected by a systemic inflammatory response (15). Extraarticular signs, particularly inflammatory eye symptoms can be present in many patients (16).

We report here four cases of patients who presented to our Rheumatology department with high titres of anti-CCP and RF but with symptoms that fit a clinical diagnosis of a SpA, including reactive arthritis. We present a comparison of their clinical manifestations and radiographic features, markers of inflammation, as well as treatment regimens. We also reviewed the literature regarding similar case-reports and previous evidence of presence of positive anti CCP antibodies in patients with SpA. 


\section{PATIENTS AND METHODS}

\section{Case Report 1}

A 46-year-old female patient was diagnosed with seropositive RA in 2011 (anti-CCP antibodies, RF antibodies and antinuclear antibodies positive). The patient was treated with methotrexate from the time of her diagnosis (which was close to the onset of her symptoms), and was on a stable dose of $15 \mathrm{mg}$ subcutaneously (SC), once weekly, and additional intermittent treatment with naproxen.

This patient was referred to our clinic seeking a second opinion with regard to previous radiographic evidence of bilateral SII (on repeated assessments in 2012 and 2015). At the time of the referral, the patient complained of inflammatory low back pain, mainly affecting the lumbosacral area, radiating down to her buttocks, and occasional hip pain. The pain was associated with early morning stiffness and was present at night as well. On further questioning, the patient described dry eyes with possible episodes of eye redness in the past but had never received a diagnosis of iritis or keratitis. She denied significant changes in her bowel habit and stool appearance and had never had a diagnosis of inflammatory bowel disease.

On examination, there was no evidence of tender or swollen peripheral joints, enthesitis or dactylitis, but she described intermittent pain (arthralgia) in her fingers and had localised SII joint pain with well-preserved mobility within her spine. The patient had no history of hypermobility or pelvic trauma. She was tested HLA-B27 positive.

In order to appreciate if her inflammatory sounding low back pain was associated with ongoing inflammation of her SIJs, we performed an MRI scan of her lumbar spine and SIJs. The MRI report described erosions of the SIJ margins bilaterally and marked bone marrow oedema of the sacral margin of the right SIJ, in keeping with a combination of active and chronic SII (Figure 1) and no evidence of spinal inflammation. In addition, we performed an ultrasound examination of her hands, which revealed chronic erosions and synovial hypertrophy, without Doppler signal, suggesting well-controlled, erosive RA. The patient was treated with two different courses of NSAIDs for a duration of 4 weeks, but experienced no significant clinical improvement, and was initiated on biologic treatment with anti-TNF blockade afterwards.

\section{Case Report 2}

A 54-year-old Bangladeshi woman was admitted to our inpatient service with a 2-week history of fever and progressive right-sided hip pain, with significant difficulty mobilising herself. She denied lower back or buttock pain and any other arthralgia. Additionally, there was no 
evidence of other infective symptoms, apart from dysuria. She travelled recently to Bangladesh for 3 weeks, but denied any history of tuberculosis (TB) or recent TB contact. Her past medical history was significant for hypertension, hyperthyroidism, vitamin $D$ deficiency, pituitary microprolactinoma. She was also a smoker (10 pack/year) and had no personal or family history or inflammatory arthritis.

On examination, the right hip had good range of movement with tenderness on external rotation and over the lateral aspect of her thigh. The joint itself was neither hot nor tender and there was no evidence of skin infective changes or enlarged inguinal lymph nodes. Her neurological examination was unremarkable. On her blood results, inflammatory markers were elevated; CRP was $>100 \mathrm{mg} / \mathrm{l}$, the anti CCP antibodies and RF were strongly positive, and all the other blood tests were normal. The urinalysis showed urinary infection with E.Coli which was treated with Nitrofurantoin. Pelvic X-rays showed mild degenerative changes in both hips.

MRI demonstrated a moderate right hip joint effusion, hip synovitis and periarticular soft tissue inflammation (Figure 2). Furthermore, the scan revealed some mild sclerosis and irregularity at the anterior inferior margin of the right sacroiliac joint, without signs of active SII. The patient was treated with intramuscular steroid injection in addition to analgesia (NSAIDs and paracetamol) and her symptoms improved significantly after 5 days. She was discharged for follow up in the outpatient clinics. From a functional perspective, the patient has continued to improve her mobility and the hip pain subsided. Her follow-up blood tests showed resolution of the systemic inflammatory response and normal urinalysis. In light of both a clinical and biochemical improvement, the clinical appreciation was that the patient developed acute hip arthritis secondary to urinary infection with E Coli with complete clinical resolution of symptoms.

\section{Case Report 3}

A 56-year-old female patient was referred to our in-patient service for longstanding history of lower back pain. In October 2009 she had been operated on for a slipped disc at L4-L5 level and following surgical intervention, the patient had been symptom-free for approximately two years. Since 2011 her pain had returned and changed pattern, as she experienced left thigh radiation of her low back pain associated with early morning stiffness lasting approximately one hour, which improved with activity. She was treated with diclofenac followed by naproxen, but was unable to tolerate any of the anti-inflammatories because of associated abdominal discomfort. She received a previous diagnosis of RA of the SIJ based on repeated MRI scans, which demonstrated evidence of right SII in association to strongly positive anti CCP antibodies (in association with L4-L5 disc degenerative changes without nerve compression). 
Her history was significant for an episode of acute iritis, bruxism and type 2 diabetes mellitus, but no history of hypermobility or arthritis. The patient was a previous smoker but quit 8 years ago. The patient had no symptoms of psoriasis or inflammatory bowel disease and was peri-menopausal.

On examination, there was restricted mobility in anterior flexion of the lumbar spine with a fingers-to-floor index of $20 \mathrm{~cm}$ and a restricted lateral flexion. Schober's manoeuvre found 4 $\mathrm{cm}$ expansion of the lumbar spine with anterior flexion. She had low back pain with right SIJ pain on palpation, pain over the trochanteric area, but no evidence of peripheral arthralgia, synovitis or dactylitis. The rest of her clinical examination was within normal limits. A repeated MRI organised after clinical review showed pronounced left SII (Figure 3). Based on spinal pain severity and BASDAI score, associated with poor response to NSAIDs, the patient was initiated on treatment with anti TNF agents, and improved clinically when evaluated after 6 months.

\section{Case report 4}

A 23-year-old female patient was referred to the rheumatology outpatient clinics for symptoms of inflammatory sounding hand and low back pain. There was no relevant personal or family medical history. Extensive investigations showed strongly positive anti CCP antibodies, positive HLA-B27, increased inflammatory markers, normal radiographs of hands and feet, and sclerosis of the left SIJ and joint space narrowing affecting both the hip and SIJ on the left hand-side on pelvis Xrays (Figure 4). Further MRI imaging found active left SII and left hip synovitis, and the US examination of hands and feet was normal. The patient was started on a trial of two different NSAIDs and a guided steroid injection for her hip was organised. A follow-up to review progression of her symptoms was organised, with regard to escalating her therapy in the case of unsatisfactory response to NSAIDs.

We detailed below the clinical, laboratory and imaging features of the case reports (Table 1 ).

\section{DISCUSSION}

Seronegative arthritis is defined by the absence of RF and anti CCP antibodies, characteristic SIJ and peripheral joint involvement and associated pathology (such as psoriasis, inflammatory eye and bowel disease). While there are similarities among the clinical entities included in this group of SpAs, there are also specific characteristics of each of these conditions that help distinguish them. The diagnosis of different types of inflammatory arthritis is facilitated by imaging, with ultrasound examination being the most commonly used imaging modality for assessing active inflammatory changes in RA (17), while MRI imaging is included in the classification criteria for SpAs (18). 
The presence of anti CCP is of particular importance in RA due to its high specificity and its use as a prognostic factor for joint erosion and disease progression (19). A large study reported a prevalence of $4 \%$ of anti CCP positive in AS patients with peripheral joint involvement and associated female predominance (20); although, the novelty of the cases presented here is that the antibodies were found in patients with exclusive axial involvement. Anti CCP antibodies were also present in other rheumatic conditions, being found in $10.6 \%$ of patients with psoriatic arthritis, $20.9 \%$ of patients with unclassified rheumatism in another study (21). There are also case-reports of concomitant diagnosis of seropositive RA and bilateral SII in some patients $(22,23)$, and the authors suggested that the prevalence of SpA features in patients with RA may be much higher than previously recognised.

The citrullination process is well recognised as associated with the tuberculosis infection, and cases of Poncet's disease with peripheral involvement and positive anti CCP antibodies have also been reported (24); however, there are no previous reports of reactive arthritis without peripheral joint involvement secondary to other bacterial infections than tuberculosis as the one we present here. The particularity of our case is that the clinical presentation of reactive arthritis without features of RA was associated with strongly positive anti CCP antibodies, which is different from previous reports of co-existence of RA and reactive arthritis $(25,26)$.

The four patients in this report had various clinical presentations; while only one had an initial diagnosis of seropositive RA with concomitant involvement of the SIJ found later on imaging, suggesting a co-existence of two different diseases. The other three patients, one with symptoms of mono-arthritis in the context of recent urinary infection, and two with inflammatory asymmetric SII had no clinical or imaging evidence of peripheral polyarthritis, which was identified as more commonly associated with the presence of anti CCP antibodies in patients with SpA (20). All four patients had high titres of anti-CCP antibodies and were females, and two out of four were smokers or ex-smokers. None of the patients had family history of RA. Only two patients were HLA-B27 positive and both had MRI evidence of active SII.

This mini case-series raised clinician awareness about the possibility of the association of clinical features typical for SpA and high titre of anti CCP antibodies in the absence of peripheral arthritis, which has not been reported before. A further follow up of these patients is required to assess if they are at risk of developing overt clinical features of both diseases (RA and SpA), and to establish optimal therapeutic options needed to ensure long term disease control. 
Table 1: Summary of the case-reports' characteristics.

\begin{tabular}{|c|c|c|c|c|}
\hline & Case 1 & Case 2 & Case 3 & Case 4 \\
\hline Sex/Age & $\mathrm{F} / 46$ & $\mathrm{~F} / 54$ & $\mathrm{~F} / 56$ & $F / 23$ \\
\hline $\begin{array}{l}\text { Clinical } \\
\text { features of } \\
\text { RA }\end{array}$ & Yes & No & No & No \\
\hline $\begin{array}{l}\text { Smoking } \\
\text { status }\end{array}$ & Ex-smoker & Smoker & Non-smoker & Non-smoker \\
\hline RF & Yes & Yes & Yes & Yes \\
\hline $\begin{array}{l}\text { CCP (>3 times } \\
\text { upper limit) }\end{array}$ & Yes & Yes & Yes & Yes \\
\hline $\begin{array}{l}\text { US of small } \\
\text { joints for } \\
\text { assessment } \\
\text { of RA activity }\end{array}$ & $\begin{array}{l}\text { Evidence of } \\
\text { erosions and } \\
\text { well-controlled } \\
\text { disease }\end{array}$ & $\mathrm{N} / \mathrm{A}$ & Normal & Normal \\
\hline $\begin{array}{l}\text { Presence of } \\
\text { active SII on } \\
\text { MRI }\end{array}$ & Yes / bilateral & No & Yes / unilateral & Yes / unilateral \\
\hline $\begin{array}{l}\text { Hip synovitis } \\
\text { on MRI }\end{array}$ & No & Yes & No & Yes \\
\hline HLA B 27 & Positive & Negative & Negative & Positive \\
\hline $\begin{array}{l}\text { Clinical } \\
\text { picture of } \\
\operatorname{ReA}\end{array}$ & No & Yes & No & No \\
\hline $\begin{array}{l}\text { Infection } \\
\text { preceding } \\
\text { the onset of } \\
\text { arthritis }\end{array}$ & No & $\begin{array}{l}\text { UTI with E Coli } \\
\text { ( } 2 \text { weeks prior } \\
\text { to arthritis } \\
\text { onset) }\end{array}$ & No & No \\
\hline $\begin{array}{l}\text { Bowel } \\
\text { inflammatory } \\
\text { symptoms }\end{array}$ & No & No & No & No \\
\hline $\begin{array}{l}\text { Eye } \\
\text { inflammatory } \\
\text { symptoms }\end{array}$ & $\begin{array}{l}\text { Possible } \\
\text { keratitis in the } \\
\text { past }\end{array}$ & No & $\begin{array}{l}\text { Uveitis in the } \\
\text { past }\end{array}$ & No \\
\hline Psoriasis & No & No & No & No \\
\hline Treatment & $\begin{array}{l}\text { MTX } \\
\text { NSAIDs } \\
\text { Anti TNF } \\
\text { therapy }\end{array}$ & $\begin{array}{l}\text { Steroids } \\
\text { NSAIDs }\end{array}$ & $\begin{array}{l}\text { NSAIDs } \\
\text { Physiotherapy } \\
\text { Acupuncture } \\
\text { Anti TNF therapy }\end{array}$ & $\begin{array}{l}\text { NSAIDs } \\
\text { Physiotherapy }\end{array}$ \\
\hline
\end{tabular}




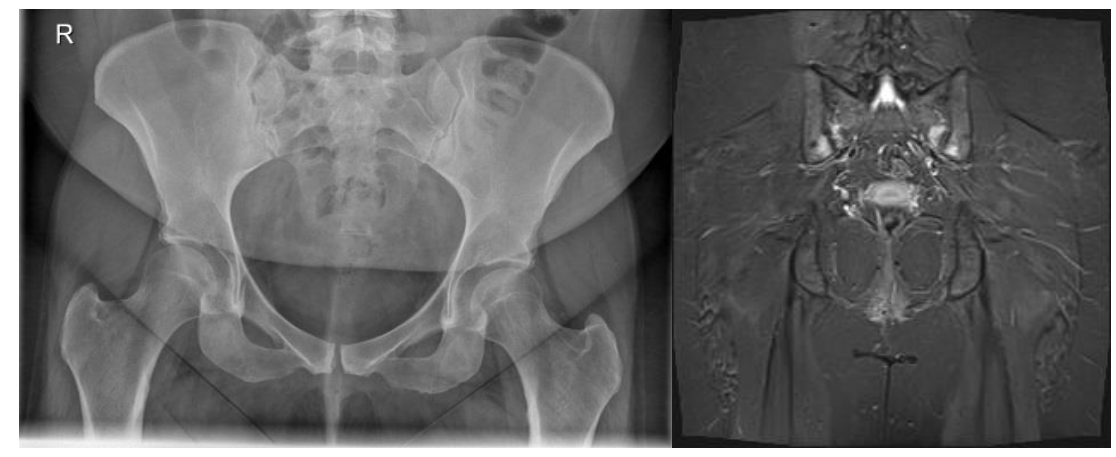

Figure 1: Bilateral SII (joint space narrowing and sclerosis on pelvic Xray and bone marrow oedema on MRI) in a patient with symmetrical polyarthralgia, in the context of previous diagnosis of RA associated with strongly positive anti CCP antibodies.

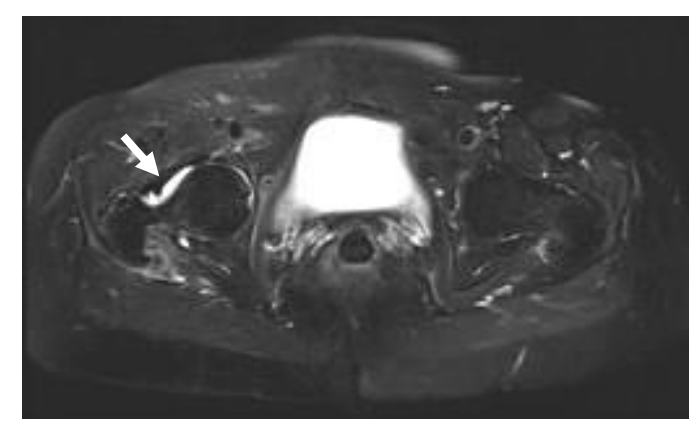

Figure 2: Right hip effusion and synovitis in a patient with clinical picture of reactive arthritis and strongly positive anti CCP antibodies, following urinary infection with E. Coli (postcontrast MRI).

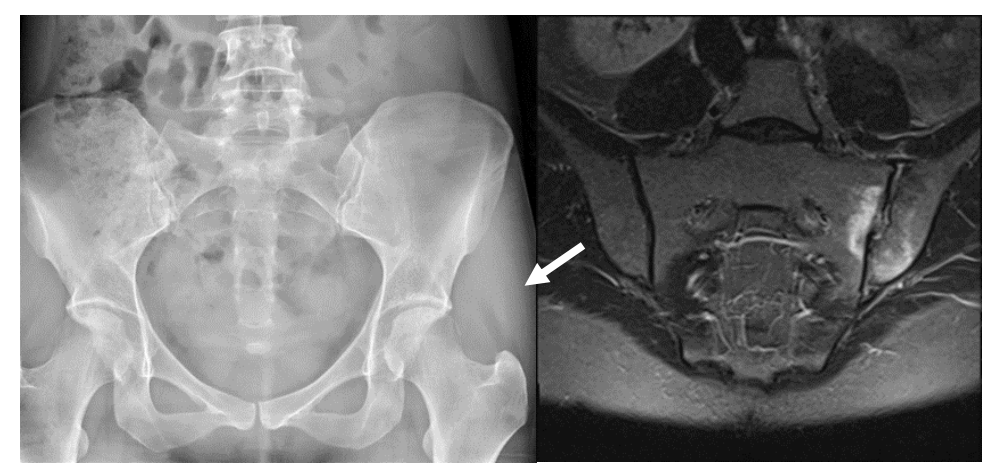

Figure 3: Left SII in a patient with strongly positive CCP antibodies and inflammatory spinal pains (pseudo widening of the joint space and bone irregularities of the left SIJ on conventional radiograph and bone marrow oedema affecting both sides of the joint on postcontrast MRI). 


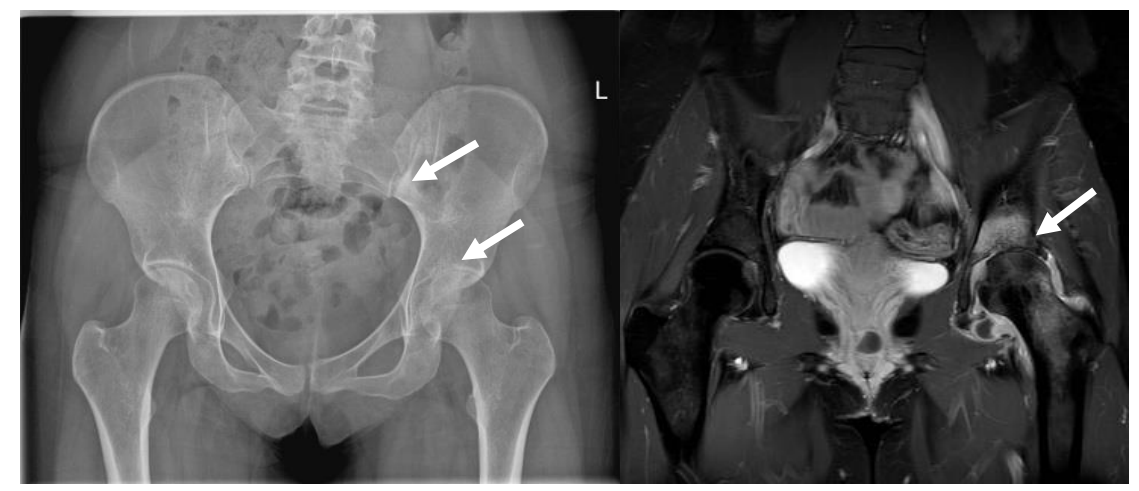

Figure 4: Left hip arthritis with significant joint space narrowing and left SII associated with bone sclerosis on conventional radiograph, and massive synovitis on MRI (post-contrast) in a patient with strongly positive anti CCP antibodies.

\section{REFERENCES:}

1. Symmons D, Turner G, Webb R, Asten P, Barrett E, Lunt M, et al. The prevalence of rheumatoid arthritis in the United Kingdom: new estimates for a new century. Rheumatology. 2002 Jul;41(7):793-800. PubMed PMID: 12096230.

2. Zhang T, Pope J. Cervical spine involvement in rheumatoid arthritis over time: results from a meta-analysis. Arthritis Res Ther. 2015 May 31;17:148. PubMed PMID: 26026719. Pubmed Central PMCID: PMC4449959.

3. Aletaha D, Neogi T, Silman AJ, Funovits J, Felson DT, Bingham CO, 3rd, et al. 2010 rheumatoid arthritis classification criteria: an American College of Rheumatology/European League Against Rheumatism collaborative initiative. Ann Rheum Dis. 2010 Sep;69(9):1580-8. PubMed PMID: 20699241.

4. Niewold TB, Harrison MJ, Paget SA. Anti-CCP antibody testing as a diagnostic and prognostic tool in rheumatoid arthritis. QJM. 2007 Apr;100(4):193-201. PubMed PMID: 17434910.

5. van Boekel MA, Vossenaar ER, van den Hoogen FH, van Venrooij WJ. Autoantibody systems in rheumatoid arthritis: specificity, sensitivity and diagnostic value. Arthritis research. 2002;4(2):87-93. PubMed PMID: 11879544. Pubmed Central PMCID: 128920.

6. Lee DM, Schur PH. Clinical utility of the anti-CCP assay in patients with rheumatic diseases. Ann Rheum Dis. 2003 Sep;62(9):870-4. PubMed PMID: 12922961. Pubmed Central PMCID: PMC1754666. 
7. Schellekens GA, Visser $H$, de Jong BA, van den Hoogen FH, Hazes JM, Breedveld FC, et al. The diagnostic properties of rheumatoid arthritis antibodies recognizing a cyclic citrullinated peptide. Arthritis and rheumatism. 2000 Jan;43(1):155-63. PubMed PMID: 10643712.

8. Scott IC, Steer S, Lewis CM, Cope AP. Precipitating and perpetuating factors of rheumatoid arthritis immunopathology: linking the triad of genetic predisposition, environmental risk factors and autoimmunity to disease pathogenesis. Best Pract Res Clin Rheumatol. 2011 Aug;25(4):447-68. PubMed PMID: 22137917.

9. Stolt P, Bengtsson C, Nordmark B, Lindblad S, Lundberg I, Klareskog L, et al. Quantification of the influence of cigarette smoking on rheumatoid arthritis: results from a population based case-control study, using incident cases. Ann Rheum Dis. 2003 Sep;62(9):835-41. PubMed PMID: 12922955. Pubmed Central PMCID: 1754669.

10. Wright V. Seronegative polyarthritis: a unified concept. Arthritis and rheumatism. 1978 Jul-Aug;21(6):619-33. PubMed PMID: 83870.

11. Rudwaleit $M$, van der Heijde D, Landewe R, Akkoc N, Brandt J, Chou CT, et al. The Assessment of SpondyloArthritis International Society classification criteria for peripheral spondyloarthritis and for spondyloarthritis in general. Ann Rheum Dis. 2011 Jan;70(1):25-31. PubMed PMID: 21109520.

12. van den Berg R, de Hooge $M$, Rudwaleit $M$, Sieper J, van Gaalen F, Reijnierse $M$, et al. ASAS modification of the Berlin algorithm for diagnosing axial spondyloarthritis: results from the SPondyloArthritis Caught Early (SPACE)-cohort and from the Assessment of SpondyloArthritis international Society (ASAS)-cohort. Ann Rheum Dis. 2013 Oct;72(10):164653. PubMed PMID: 23139266.

13. Selmi C, Gershwin ME. Diagnosis and classification of reactive arthritis. Autoimmunity reviews. 2014 Apr-May;13(4-5):546-9. PubMed PMID: 24418301.

14. Kaarela K, Jantti JK, Kotaniemi KM. Similarity between chronic reactive arthritis and ankylosing spondylitis.A 32-35-year follow-up study. Clinical and experimental rheumatology. 2009 Mar-Apr;27(2):325-8. PubMed PMID: 19473576.

15. Sengul I, Akcay-Yalbuzdag S, Ince B, Goksel-Karatepe A, Kaya T. Comparison of the DAS28-CRP and DAS28-ESR in patients with rheumatoid arthritis. International journal of rheumatic diseases. 2015 Jul;18(6):640-5. PubMed PMID: 26013310.

16. Mielants $\mathrm{H}$, Van den Bosch F. Extra-articular manifestations. Clinical and experimental rheumatology. 2009 Jul-Aug;27(4 Suppl 55):S56-61. PubMed PMID: 19822047.

17. Porta F, Radunovic G, Vlad V, Micu MC, Nestorova R, Petranova T, et al. The role of Doppler ultrasound in rheumatic diseases. Rheumatology. 2012 Jun;51(6):976-82. PubMed PMID: 22253027.

18. Sieper J, Rudwaleit M, Baraliakos X, Brandt J, Braun J, Burgos-Vargas R, et al. The Assessment of SpondyloArthritis international Society (ASAS) handbook: a guide to assess spondyloarthritis. Ann Rheum Dis. 2009 Jun;68 Suppl 2:ii1-44. PubMed PMID: 19433414.

19. Meyer O, Labarre C, Dougados M, Goupille P, Cantagrel A, Dubois A, et al. Anticitrullinated protein/peptide antibody assays in early rheumatoid arthritis for predicting five year radiographic damage. Ann Rheum Dis. 2003 Feb;62(2):120-6. PubMed PMID: 12525380. Pubmed Central PMCID: 1754441.

20. Kim JO, Lee JS, Choi JY, Lee KH, Kim YB, Yoo DH, et al. The relationship between peripheral arthritis and anti-cyclic citrullinated peptide antibodies in ankylosing spondylitis. Joint, bone, spine : revue du rhumatisme. 2013 Jul;80(4):399-401. PubMed PMID: 23141717. 
21. Payet J, Goulvestre C, Biale L, Avouac J, Wipff J, Job-Deslandre C, et al. Anticyclic citrullinated peptide antibodies in rheumatoid and nonrheumatoid rheumatic disorders: experience with 1162 patients. The Journal of rheumatology. 2014 Dec;41(12):2395-402. PubMed PMID: 25274898.

22. Azevedo VF, Buiar PG. Concurrent rheumatoid arthritis and ankylosing spondylitis in one patient: the importance of new classification criteria. Revista brasileira de reumatologia. 2013 Feb;53(1):111-9. PubMed PMID: 23588521.

23. Toussirot E, Acquaviva PC. Coexisting rheumatoid arthritis and ankylosing spondylitis discussion of 3 cases with review of the literature. Clinical rheumatology. 1995 Sep;14(5):55460. PubMed PMID: 8549095.

24. Ariza-Prota M, Pando-Sandoval A, Garcia-Clemente M, Casan P. Poncet's disease mimicking rheumatoid arthritis in a patient with suspected Crohn's disease. Clinical case reports. 2016 Jan;4(1):72-5. PubMed PMID: 26783440. Pubmed Central PMCID: 4706396.

25. Fallahi S, Miller RK, Halla JT. Coexistence of Reiter's syndrome and rheumatoid arthritis in a genetically susceptible individual. Ann Rheum Dis. 1983 Apr;42(2):210-2. PubMed PMID: 6601934. Pubmed Central PMCID: 1001103.

26. de Mendonca LL, Coelho VP, Meirelles Ede S, Rodrigues CJ, Balthazar PA. [Coexistence of rheumatoid arthritis and Reiter's syndrome: a case report and review of the literature]. Revista do Hospital das Clinicas. 1986 May-Jun;41(3):132-5. PubMed PMID: 3563302. Coexistencia de artrite reumatoide e sindrome de Reiter: relato de caso e resumo de literatura. 